\title{
Synthesis and Mass Spectrum Characterization of Lyrame Schiff base for Synthetic Ingredients in Perfumes Industry
}

\author{
CANDRA IRAWAN ${ }^{1}$, DIAN ISLAMIYATI ${ }^{1}$, RIKA PERDANA PUTRI², \\ MOHAMMAD JIHAD MADIABU ${ }^{1 *}$ and SUPRIYONO ${ }^{1}$ \\ 'Department of Chemical Analysis, Politeknik AKA Bogor, Bogor 16154, Indonesia. \\ ${ }^{2} \mathrm{PT}$. Nilam Widuri, Bogor Indonesia. \\ ${ }^{*}$ Corresponding author E-mail : mjihad1991@gmail.com \\ http://dx.doi.org/10.13005/ojc/340657
}

Received: October 27, 2018; Accepted: November 20, 2018)

\begin{abstract}
Fragrance was a common material in human daily life. It has unique property, especially in odor. Lyrame was a synthetic precursor that was added to fragrance to increase fragrance stability and make odor last longer. Lyrame can be synthesized by using simple condensation method. This method was effective and low cost. The synthesis of lyrame uses lyral and methyl anthranilate as a precursor. The weighting methyl anthranilate was mixed to lyral solution, then heated and stirred at temperature $110 \pm 5^{\circ} \mathrm{C}$ for 30 minutes. The characterization of lyrame comprised organoleptics test and chemical structure. The organoleptics for product was color test. The chemical structure was analyzed by gas chromatography-mass spectrometry (GC-MS). Based on result from experiment, color of lyrame product was light yellow. The color of product depends on time of synthesis and concentration of precursor. The mass fragmentation pattern exhibiting the lyrame has been synthesized successfully.
\end{abstract}

Keyword: Perfumes, Schiff base, Lyrame, GC-MS, Simple Condensation.

\section{INTRODUCTION}

The majority of personal-care such as cosmetic and perfumes contains fragrances in their ingridients ${ }^{1}$. Fragrance contains many components which have generated special properties, especially in odor. Ingredient of fragrance usually contains synthetic precursor or natural extract which is diluted in alcohol. Natural precursor provides unique odor ${ }^{2}$, but it has not been priority today due to dependence on weather condition which can disrupt the supply chain. Nowadays, synthetic precursor has been used to subtitute the natural source as a main ingredient ${ }^{3}$.

Quality of fragrance can be known from some properties, like odor, color, volatility, and other physical chemical stabilities ${ }^{4,5,6}$. Generally, a synthetic precursor is a Schiff Base like aurantiol ${ }^{4}$, verdantiol, cyclantin, jasmea, and the most promising lyrame is added to escalate the quality of fragrances. Molecular weight of lyrame is bigger than other

This is an Open Access article licensed under a Creative Commons license: Attribution 4.0 International (CC- BY). Published by Oriental Scientific Publishing Company @ 2018 
ingredients in fragrance, so lyrame Schiff base has good stabilty and less volatile. Its properties enhance the recilience of fragrance blend.

Aldehyde compound is reacted with amine trapping agent in condensation reaction to form Schiff base and water as a by-product. Water must be eliminated to prevent turbidity and two phases formed in product solution. Generally, eliminating water from product occurs under vacuum, instead using high temperature at atmospheric pressure to prevent Schiff bases product is not decomposing ${ }^{3}$. The reaction of Schiff base synthesis as follows:<smiles>[R]CN=C[C+]=C=C</smiles>

Fig. 1. The formation reaction of Schiff base

Methyl anthranilate was often used as amine trapping agent in Schiff base's synthesis. Methyl anthranilate generally gives Schiff bases that are yellow solid or viscous, yellow liquid. An excess methyl anthranilate was used to make Schiff base become more liquid. Methyl anthranilate is a primary amine which will react spontaneously with an alkyl aldehyde ${ }^{7}$, terpened aldehyde $e^{7,8}$, or terpened-like aldehyde $^{7}$ such as lyral. When methyl anthranilate reacts with lyral, Schiff base called lyrame is formed.

Gas chromatograpy and mass spectrometry (GC-MS) have been the most important techniques in the perfumes industry because perfume ingridient is quite complex, a polar, and (semi) volatile ${ }^{9,10,11}$. In this study, we aim to prepare lyrame Schiff Base using simple condensation reaction and to analyze spectral molecular ion fragment to ensure molecular structure lyrame Schiff base using GC-MS.

\section{EXPERIMENTAL}

\section{Synthesis of Lyrame}

$9,070 \mathrm{~g}$ methyl anthranilate solution was mixed with lyral solution in beaker glass. The mixture solution was heated and stirred at temperature about $110 \pm 5^{\circ} \mathrm{C}$ for 30 minutes.

\section{Characterization of Lyrame}

Color test. Lyrame Schiff base was added to reaction tube $($ diameter $=1.3 \mathrm{~cm}$; height $=$
$10 \mathrm{~cm}$ ), then panelist wrote some codes to identify the solution. Panelist's eyes must be parallel with the tube, when they did the test. The room condition must have good light exposure and no reflection to increase the test accuracy.

GC-MS. Lyrame schiff base solution was diluted by ethanol, then analysed using GC-MS. The analysis on condition of GC-MS could be seen at Table 1 below. Chemical composition of lyrame was confirmed by comparing fragmentation result with existing library.

Table 1: GC-MS Analysis condition

\begin{tabular}{|c|c|}
\hline & Information \\
\hline Colomn & $\begin{array}{l}\text { Capillary colomn : HP-5 } \\
(5 \% \text { Phenyl Methyl } \\
\left.\text { Siloxane } 325^{\circ} \mathrm{C}\right)\end{array}$ \\
\hline Carrier Gas & Helium \\
\hline Carrier Gas Pressure & 7,0531 psi \\
\hline Injector Temperature & $100^{\circ} \mathrm{C}$ \\
\hline Injection Volume & $0,2 \mu \mathrm{L}$ \\
\hline Injection Technique & Split \\
\hline Split Ratio & $80: 1$ \\
\hline \multicolumn{2}{|c|}{ Temperature Program (Colomn) } \\
\hline Initial Temperature & $100^{\circ} \mathrm{C}$ hold for $5 \mathrm{~min}$. \\
\hline Temperature Rate & $15^{\circ} \mathrm{C}$ per minutes \\
\hline Final temperature & $250^{\circ} \mathrm{C}$ hold for $5 \mathrm{~min}$. \\
\hline Interval & $25 \mathrm{~min}$. \\
\hline
\end{tabular}

\section{RESULT AND DISCUSSION}

Lyrame was produced by simple condensation reaction. Amine group in methyl anthranilate would act as a nucleophillic, attacking the carbonyl group in lyral by 1,2 addition, then hydroxyl group was protonized and eliminated water molecules. The lyrame mechanism synthesis is shown at Figure 2.

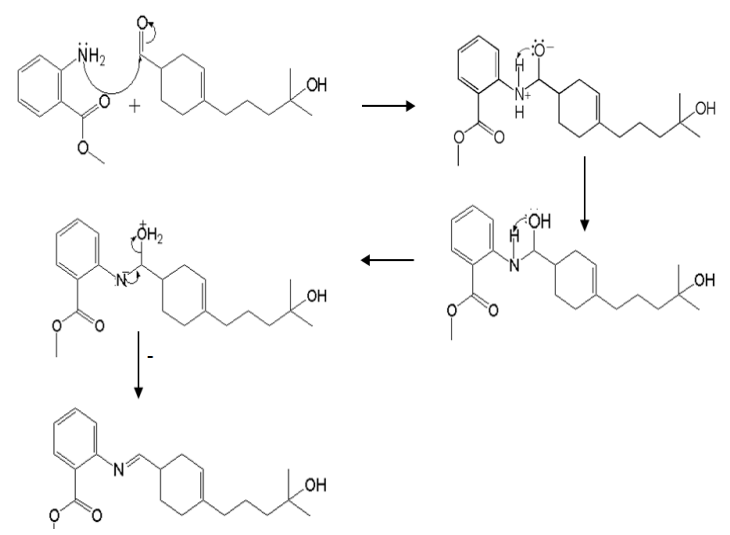

Fig. 2. Mechanism of lyrame formation reaction 
Lyrame Schiff base has a high molecular weight, meaning it has good physical and chemical stabilities, but poor solubility in water. In order to speed up the reaction, the synthesis was carried out at high temperature and stirred in hot plate. Furthermore, this process also prevented the solution turbid and formed two phases. Water would evaporate because the synthesis temperature was higher than boiling temperature of water. Stirring process during the synthesis would accelerate movement of water molecule, so would evaporate easily. The product solution was a bright yellow as shown in Figure 3.
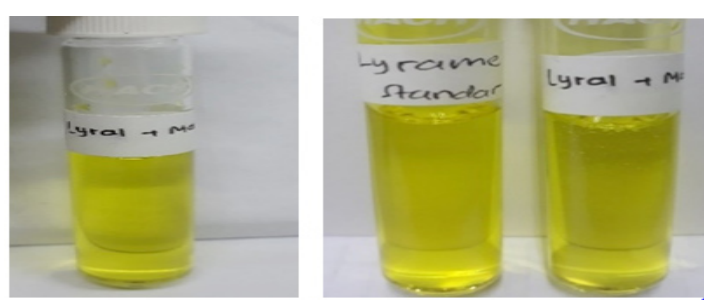

Fig. 3. (left) color of lyrame product solution; (right) lyrame product solution compared with lyrame standard solution

Color test was an important parameter for physical characterization in lyrame synthesis. Test was performed by trained panelist. The standard solution which used lyrame standard solution was made in PT Nilam Widuri. Time for synthesis of lyrame standard solution was 2 hours. Fig. 3. shows that color in lyrame was light yellow. The lyrame product was brighter than standard, it was shown that color solution directly proportional with time of lyrame synthesis.

The concentration of methyl anthranilate was also a crucial factor to determine color the Schiff base. High concentration of methyl anthranilate gave a brighter color of solution and made product less viscous. Furthermore, another crucial factor determining the quality of product (brigthness of solution) was the degree of completion of reaction.

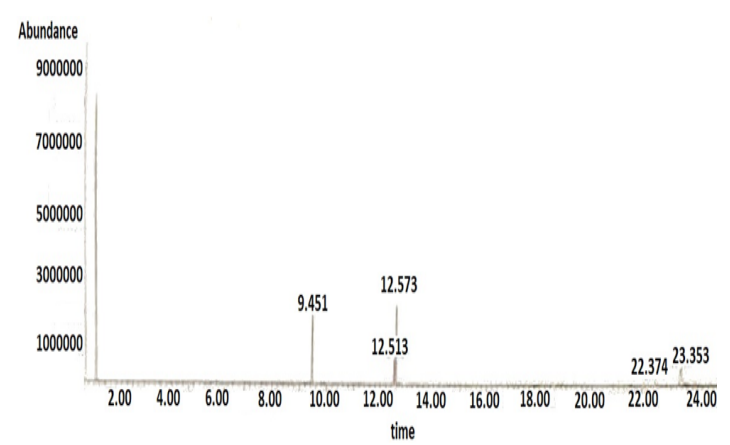

Fig. 4. GC-MS chromatogram of lyrame's synthesis
The lyrame product solution was analyzed by GC-MS to investigate lyrame molecular structure ${ }^{9,10}$. The result of GC-MS with percentage for each component was listed in Table 2. The reactant methyl anthranilate and lyral have peaks at $9.465 \mathrm{~min}$. $12.513 \mathrm{~min}$. and 12.571 minutes. It indicated that the lyrame formation was not completion. Lyral has two $\mathrm{E}-\mathrm{Z}$ isomer configurating at its cyclic structure which shown in Figure $5^{12}$.

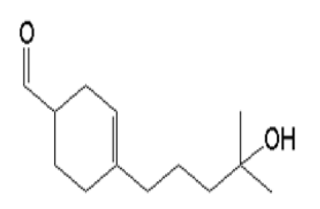

(a)

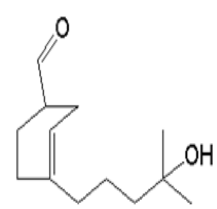

(b)
Fig. 5. Skeletal formula of lyral isomers (a) Z-Lyral, (b) E-Lyral

Steric hindrance was an interaction that influenced the conformation in the organic molecules. Steric hindrance was a critical factor to determine the reactivity and stability in molecular structure ${ }^{13}$. The molecule has less reactive in bulky molecules ${ }^{14}$. Z-lyral has less steric hindrance than E-lyral, so Z-lyral would have more reactive than other isomer. It was proved with the unequal percentage of composition between isomers. Lyrame peak was shown at $22.350 \mathrm{~min}$. and 23.371 minutes. It exhibited that all lyral isomers could react with methyl anthranilate to form lyrame.

Table 2: Result of GC-MS analysis

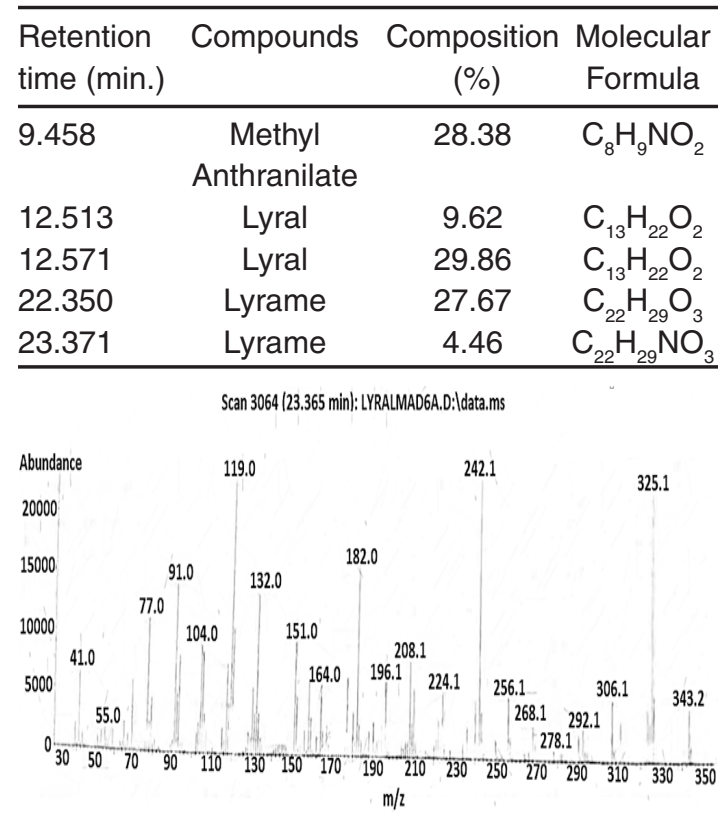

Fig. 6. Mass spectrum of Lyrame from synthesis 
Molecular structure of lyrame was investigated by using ion fragment from mass spectrometry. Fig. 6 shows that mass spectral for lyrame product $\mathrm{m} / \mathrm{z} 343$ was similar with lyrame's molecular mass and m/z 119.0 was the base peak. Mass spectra $\mathrm{m} / \mathrm{z} 325$ was originating from alpha cleavage releasing $\mathrm{H}_{2} \mathrm{O}$ molecule. There were two possibilities of carbocation in $\mathrm{m} / \mathrm{z} 325$ tertiary and secondary positions. Double homolytic cleavages occurred in tertiary carbocation to produce $\mathrm{C}_{3} \mathrm{H}_{5}{ }^{+}$ which was shown as $\mathrm{m} / \mathrm{z} 41$. At secondary carbocation experiences the homolytic cleavage and $\mathrm{C}_{4} \mathrm{H}_{7}{ }^{+}$were made. It was proved by peak of $\mathrm{m} / \mathrm{z}$ 55 risen in fragmentation spectrum. Another route radical cleavage of secondary carbocation would release $\mathrm{C}_{5} \mathrm{H}_{9}$ radical and it was proved by peak of $\mathrm{m} / \mathrm{z}$ 256 in the mass spectrum. Releasing $: \mathrm{CH}_{2}$ in next homolytic cleavage, made high peak of $\mathrm{m} / \mathrm{z} 242$ arise. Molecular ion $\mathrm{C}_{15} \mathrm{H}_{16} \mathrm{NO}_{2}{ }^{+}$experience carbocation rearranged and followed by simultaneous heterolytic cleavage to release $\mathrm{HCOOCH}_{3}$. The peak of $\mathrm{m} / \mathrm{z} 77$ was originating from $\mathrm{C}_{6} \mathrm{H}_{5}{ }^{+}$which was rising after releasing $\mathrm{C}_{7} \mathrm{H}_{7} \mathrm{~N}$ radical. The base peak of $\mathrm{m} / \mathrm{z} 119$ was originating from $\mathrm{C}_{8} \mathrm{H}_{6} \mathrm{O}_{2}{ }^{+}$which experienced homolytic cleavage to form $\mathrm{C}_{7} \mathrm{H}_{3} \mathrm{O}_{2}{ }^{+}$and released methyl radical. Pattern of lyrame's mass fragmentation can be seen in Figure 6.

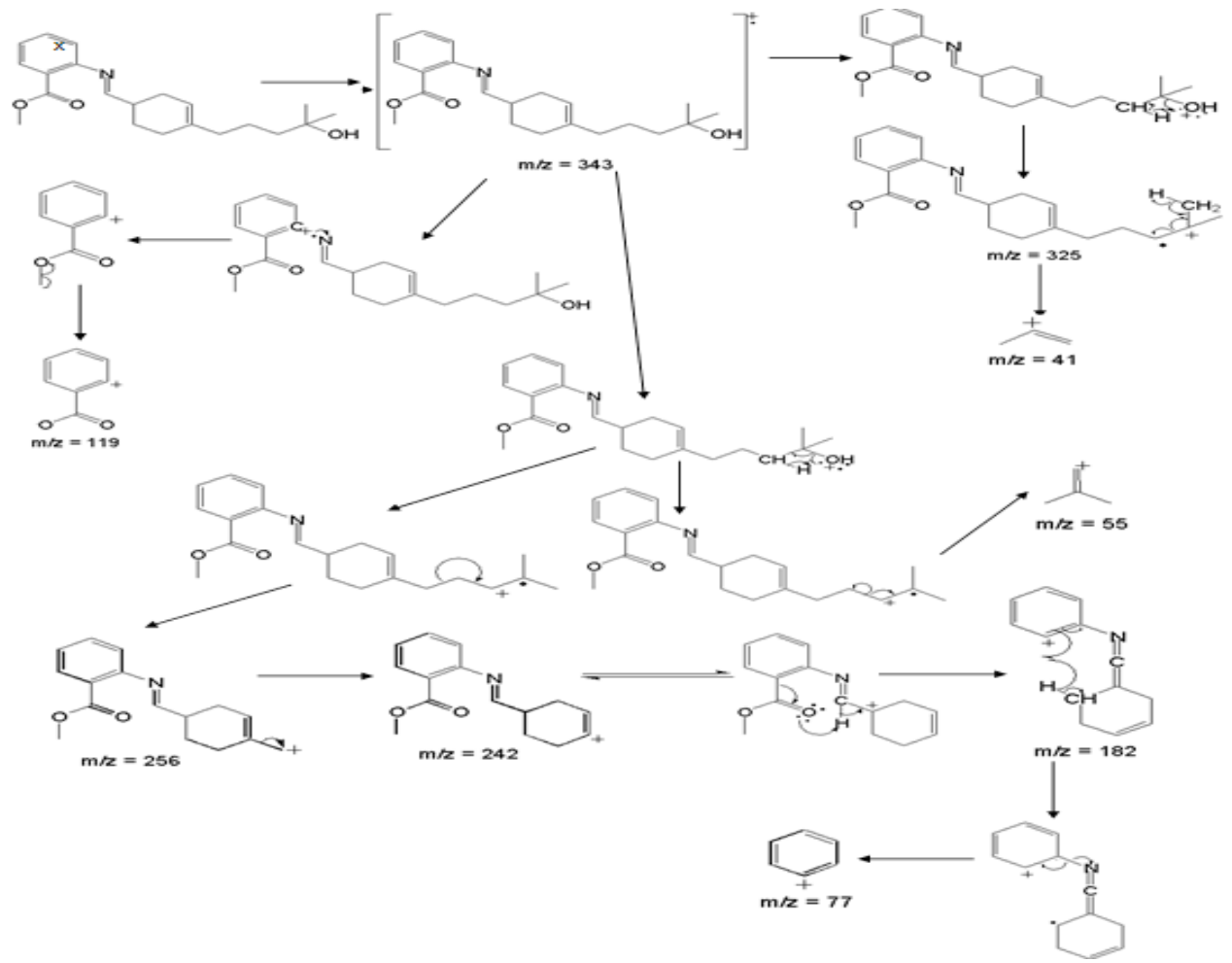

Fig. 6. Pattern of mass fragmentation of lyrame Schiff base

\section{CONCLUSION}

Lyrame Schiff base was succesfully synthesized by simple condensation method. The color of lyrame was directly proportional with time of synthesis. The degree of completion and concentration of methyl anthranilate also was crucial factor that affected the color of product. High concentration of methyl anthranilate made the product less viscous and the color of solution was brighter. Lyrame structural molecules has had been confirmed with GC-MS mass fragmentation pattern. There are two peaks of lyrame product in chromatogram due to lyral as precursor has two isomers that can be reacted with methyl anthranilate. Base peak in the lyrame fragment in $\mathrm{m} / \mathrm{z} 119$ is formed from homolytic cleavage $\mathrm{C}_{8} \mathrm{H}_{6} \mathrm{O}_{2}{ }^{+}$and the parental ions of lyrame fragment in $\mathrm{m} / \mathrm{z} 343$.

\section{ACKNOWLEDGEMENT}

This research was funded by Politeknik AKA Bogor, Ministry of Industry of Indonesia and partially supported by from PT. Nilam Widuri for GC-MS measurement. 


\section{REFERENCE}

1. Villa, C.; Gambaro, R.; Mariani, E.; Dorato, S. Journal of Pharmaceutical and Biomedical Analysis., 2007, 44, 755-762.

2. Vankar, P.S. Resonance., 2004, 9(4), 30-41.

3. Sarkic, A.; Stappen, I. Cosmetics., 2018, 5(1), 11.

4. Irawan, C.; Indryati, S.; Lestari, E. S.; Hidaningrum, A., Supriyono. Orient. J. Chem., 2018, 34(1), 394-400.

5. Quellet, C.; Schudel, M.; Ringgenberg, R. Chimia., 2001, 55, 421-428.

6. Gygax, H.; Koch, H. Chimia., 2001, 55, 401-405.

7. Surburg, H.; Panten, J. Common Fragrance and Flavor Materials. Preparation, Properties and Uses 5th Ed. Wiley-VCH Verlag GmbH \& Co. KGaA., 2006.

8. Pybus, D.; Sell, C. The Chemistry of
Fragrances: From Perfumer to Consumer $2^{\text {nd }}$ Edition. Royal Society of Chemistry., 2006.

9. Asten, A. V. Trends Anal. Chem., 2002, 21, 698-708.

10. Begnaud, F.; Chaintreau, A. Philos Trans A Math Phys Eng Sci., 2016, 374(2079), 20150365.

11. C.Debonneville, A. Chaintreau, J.Chromatogr., A, 2004, 1027, 109-115.

12. Kaloustian, J.; Mikail, C.; El-Moselhy, T.; Abou, L.; Portugal, H. OCL., 2006, 14, 110-115.

13. Bhat, K., Chang, K. J., Aggarwal, M. D., Wang, W. S., Penn, B. G., \& Frazier, D. O. Material Chemistry and Physics., 1996, 44(3), 261-266.

14. Smith, J. G. Organic Chemistry $3^{\text {rd }}$ Edition. McGraw-Hill., 2011. 